\title{
CORRECTION
}

\section{Correction to: Polymyxin B causes DNA damage in HK-2 cells and mice}

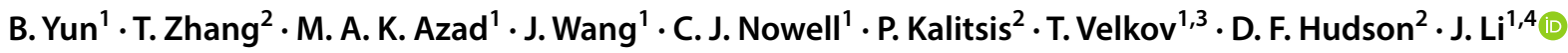

Published online: 18 June 2018

c) Springer-Verlag GmbH Germany, part of Springer Nature 2018

\section{Correction to: Archives of Toxicology}

https://doi.org/10.1007/s00204-018-2192-1

In the original publication of the article, part of Fig. 6 is missing. The missing subpanels, Fig. 6c, d are given below.

D. F. Hudson

damien.hudson@mcri.edu.au

$\bowtie \mathrm{J} . \mathrm{Li}$

jian.li@monash.edu

1 Monash Institute of Pharmaceutical Sciences, Monash University, Melbourne, Australia

2 Murdoch Children's Research Institute, Royal Children's Hospital, Melbourne, Australia

3 Department of Pharmacology and Therapeutics, University of Melbourne, Melbourne, Australia

4 Infection \& Immunity Program, Department of Microbiology, Biomedicine Discovery Institute, Monash University, Melbourne, Australia 
Fig. 6 c Time-course of PMBinduced nephrotoxicity in mice showed mean increase in foci to cell percentile of total population as time post-treatment increased, with representative examples of undamaged and damaged mouse kidney sections showing $\gamma \mathrm{H} 2 \mathrm{AX}$ foci staining. All data are presented as mean \pm SD. d Foci percentage of individual mice which showed no obvious histological damage $(n=8)$
C
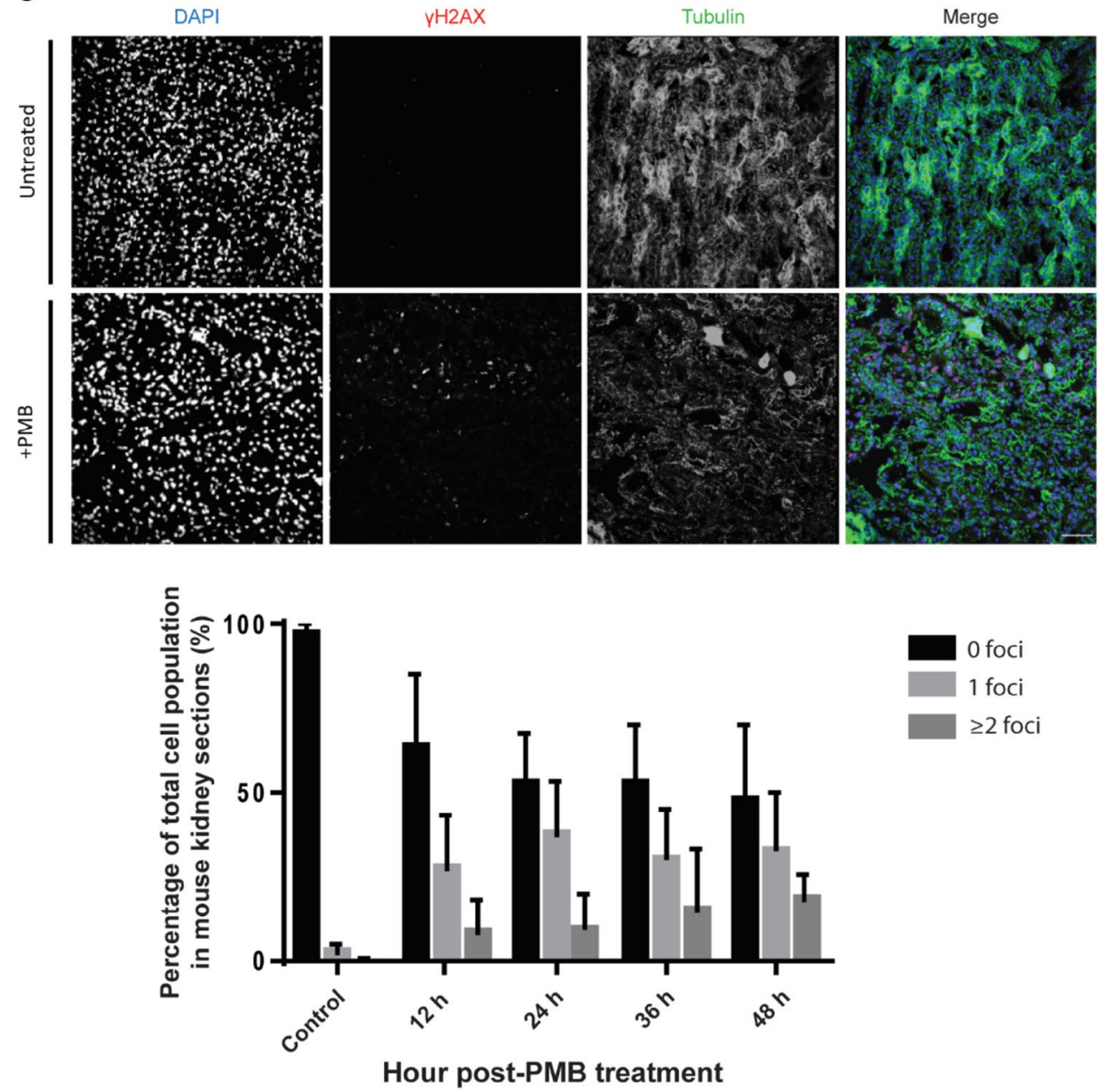

D

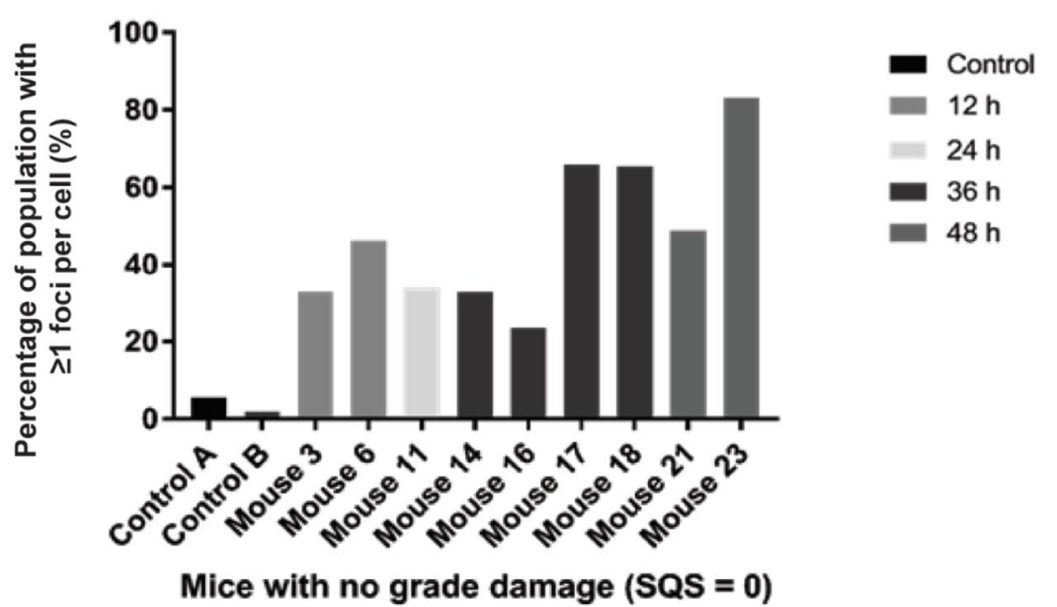

